\title{
TESTES FÍTOQUIMICOS EM EXTRATOS ORGÂNICOS DE Bixa orellana L (URUCUM)
}

\author{
F. A. SILVA*; A. M. C. BIZERRA; P. R. D. FERNANDES \\ Instituto Federal de Educação, Ciência e Tecnologia do Rio Grande do Norte \\ felipe101913@hotmail.com*
}

Submetido 13/02/2018 - Aceito 22/05/2018

DOI: $10.15628 /$ holos.2018.6929

\section{RESUMO}

Este trabalho relata a identificação de algumas classes de compostos presentes nos extratos etanólicos e hexânicos da Bixa orellana (Urucum). Para os testes fitoquímicos realizados, os extratos foram obtidos de diferentes partes da planta (folhas, sementes e caule) as quais foram secas e submetidas ao processo de extração a frio em separado com os solventes hexano e etanol. Assim, obtiveram-se os extratos etanólicos e hexânicos da espécie. As classes de compostos investigadas foram fenóis, taninos, antocianinas, antocianidinas, flavonóides, leucoantocianidinas, catequinas, flavanonas, saponinas, antraquinonas, alcalóides, triterpenóides e esteróides. Os testes apresentaram resultados positivos para alguns extratos, que revelaram a presença de flavanonas, flavonóis, xantonas, saponinas, flavonóides, antraquinonas livres, alcalóides, triterpenóides e esteróides. Conclui-se que os resultados encontrados no estudo confirmam os dados apresentados na literatura pesquisada.

PALAVRAS-CHAVE: Análise fitoquímica, bixa orellana L, metabólitos secundários.

\section{PHYTOCHEMICALS TESTS IN ORGANIC EXTRACTS Bixa Orellana L (URUCUM)}

\begin{abstract}
This work reports the identification of some classes of compounds present in the ethanolic and hexane extracts of Bixa orellana (Urucum). For the phytochemical tests carried out, the extracts were obtained from different parts of the plant (leaves, seeds and stem) which were dried and subjected to the cold extraction process separately with the solvents hexane and ethanol. Thus, the ethanolic and hexane extracts of the species were obtained. The classes of compounds investigated were phenols, tannins, anthocyanins,
\end{abstract}

anthocyanidins, flavonoids, leucoantocyanidins, catechins, flavanones, saponins, anthraquinones, alkaloids, triterpenoids and steroids. The tests showed positive results for some extracts, which revealed the presence of flavanones, flavonols, xanthones, saponins, flavonoids, free anthraquinones, alkaloids, triterpenoids and steroids. We conclude that the results found in the study confirm the data presented in the researched literature.

KEYWORDS: phytochemical analysis, bixa orellana $L$ and secondary metabolites. 


\section{INTRODUÇÃO}

Os Produtos Naturais (PN) são utilizados pelo homem desde tempos antigos. Seja a busca por alívio de enfermidade ou cura de doenças através da ingestão de ervas, folhas ou chás; o uso desses produtos foi possivelmente a sua primeira forma de utilização (VIEGAS JÚNIOR; BOLZANI, 2006).

A utilização de plantas medicinais e o conhecimento de suas propriedades terapêuticas é uma prática muito antiga. Segundo informações encontradas na literatura, um dos primeiros relatos de propriedades medicinais de plantas dos quais se tem notícia é o Papyrus Ebers do antigo Egito. E ainda se relata a existência do uso de plantas com fins medicinais em sociedade pré-histórica europeia e pré-colombiana antes de 3000 a.C. (BARREIRO, 2000).

Os testes fitoquímicos são de fundamental importância para identificar classes de compostos e na descoberta de novos constituintes químicos de espécies vegetais que poderão ter uso terapêutico. Eles podem ser realizados para identificar as mais diferentes classes de compostos orgânicos, podendo ser aplicados em diferentes tipos de extratos de todas as partes da planta.

Dessa forma, estudos fitoquímicos realizados em Bixa orellana $L$ identificaram a presença de algumas classes de compostos, como saponinas, flavonóides, taninos, alcalóides e esteróides, no caule, flor, folha, fruto, fruto verde e na raiz (STRINGHETA; SILVA, 2008).

Portanto, o objetivo deste trabalho é realizar testes fitoquímicos com os extratos etanólico e hexânico da semente, folha e caule de Bixa orellana $L$ (urucum), a fim de identificar suas principais classes de compostos constituintes.

\section{REVISÃO BIBLIOGRÁFICA}

\subsection{Metabólitos secundários e a fitoquímica}

As espécies vegetais possuem inúmeras substâncias em sua composição, as quais também são chamadas de metabólitos. Segundo Ricardo (2011) uma das principais características dos seres vivos é a atividade metabólica, que compreende um conjunto de reações químicas que ocorrem constantemente no interior das células. Nas células vegetais esse metabolismo é dividido em primário e secundário.

O metabolismo primário é constituído pelos processos metabólitos que exercem uma função indispensável nas plantas, como a fotossíntese, a respiração e o transporte de solutos. Os compostos provenientes desse processo têm uma distribuição universal, como os aminoácidos, carboidratos, lipídios, ácidos nucléicos e clorofila (RICARDO, 2011).

Os metabólitos secundários diferentemente dos primários não são essenciais à planta, mas desempenham papel importante para a diferenciação entre espécies. Contribuem com aromas, com as cores dos alimentos e com resistência contra pestes e doenças, mantendo a sobrevivência nas condições ambientais favoráveis. Portanto, esses metabólitos podem beneficiar com suas propriedades terapêuticas para curas de doenças humanas, pois é uma excelente fonte de substâncias biologicamente ativas (FUMAGALI, et al. 2008; FILHO, 2010). 
As substâncias dos metabólitos secundários por apresentarem propriedades farmacológicas de grande importância, são muito comercializadas nos setores alimentícios, agronômico, de perfumaria e principalmente farmacêutico. Vale ressaltar que devido ao grande número de metabólitos vegetais, estes têm despertado o interesse da comunidade científica, pois visam nesses, uma promissora fonte de moléculas potencialmente úteis ao homem (BEZERRA, 2008).

Segundo Fumagali et al (2008), a classificação dos metabólitos secundários é dada de acordo com sua rota biossintética, possuindo assim três grandes famílias desses compostos: os fenólicos, os terpênicos (incluindo os esteroides) e os alcalóides. A Figura 1 mostra exemplos de substâncias dessas famílias: o ácido gálico, que é um composto fenólico (A); o geraniol, que é um composto terpênico (B); e a cafeína, que é um alcaloide.<smiles>O=C(O)c1cc(O)c(O)c(O)c1</smiles>

(A)

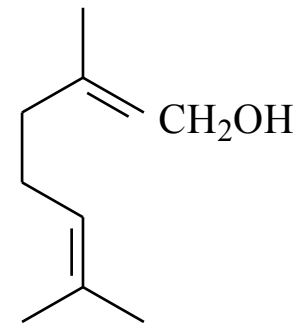

(B)<smiles>CN1CCCC1c1cccnc1</smiles>

(C)

Figura 1: Exemplo de Ácido gálico (A), Geraniol (B) e Cafeína (C).

A pesquisa fitoquímica tem como objetivo conhecer os constituintes químicos das plantas ou avaliar a sua presença. No entanto, quando ainda não se dispõem de estudos químicos sobre uma determinada espécie, a análise fitoquímica preliminar pode identificar os grupos de metabólitos secundários relevantes na mesma (SIMÕES et al, 2001).

Dessa forma, as análises e estudos fitoquímicos são essenciais para identificar a existência de determinadas classes de compostos nas plantas, especialmente nos casos onde os extratos delas apresentam bioatividade e consequentemente se pretende isolar os seus princípios ativos (SOARES, 2008).

\subsection{Bixa orellana L (Urucum)}

O urucum é uma planta pertencente à família das Bixáceas e é conhecido pelo seu nome botânico de Bixa orellana L, (ALVES, 2005). Apesar de sua denominação científica, ainda possui várias nomeações pelo mundo, urucu e urucum (Brasil); atole, achiote e bija (Peru, Colômbia e Cuba); achiote, bija, anoto (Venezuela); urukú (Paraguai); rocou e rocoyer (República Dominicana e Guiana Francesa); rocuyer (França); changuaricá e K' u-zub (México) (CUNHA, 2008).

O seu nome científico foi uma homenagem ao primeiro botânico e explorador que o estudou, Francisco de Orellana. O seu nome popular urucum vem do vocábulo indígena, que em tupi, “uru-ku" significa amarelo (COSTA, 2007). 
O urucuzeiro é um arbusto originário da América Tropical e característico da floresta amazônica, é uma árvore pequena que pode atingir de $2 \mathrm{~m}$ a $9 \mathrm{~m}$ de altura. Pode ser uma planta ornamental por apresentar belas flores e frutos (DORNELAS, 2010; ALVES, 2005; COSTA, 2007). Suas folhas são simples e alternadas, as flores são hermafroditas de coloração rósea, azul rósea e branca, geralmente situadas nas extremidades dos galhos. Das flores nascem os frutos que são cápsulas ovóides (cachopas) achatadas, que são cobertas por espinhos flexíveis, e que contém no seu interior numerosas sementes. A Figura 2 mostra o aspecto da planta do urucuzeiro.

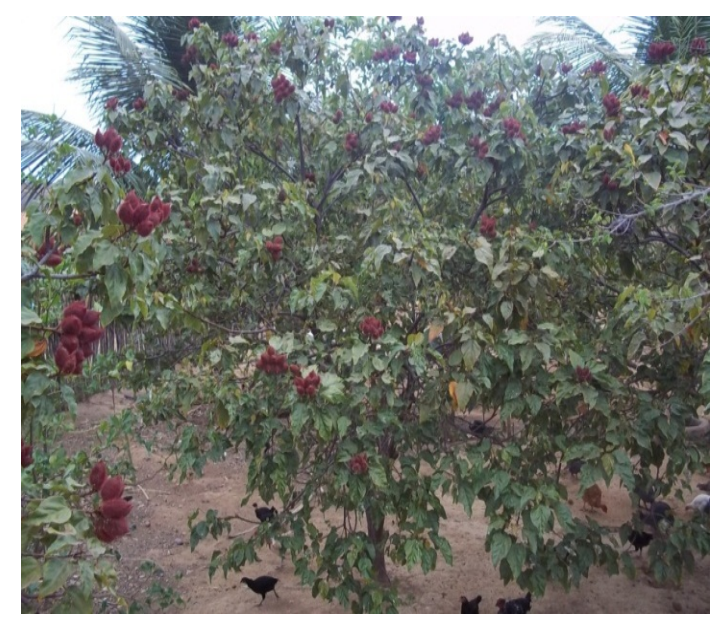

Figura 2: Urucuzeiro

Segundo Souza (2011) a coloração vermelha das sementes ocorre por causa do percentual da molécula de bixina, enquanto que quanto maior a concentração de norbixina, maior a tendência para o amarelo. Essas duas moléculas são classificadas como carotenoides, uma subclasse pertencente aos terpenos. Portanto, as sementes e os extratos processados são comercializados de acordo com o teor de bixina ou norbixina. A Figura 3 mostra as estruturas da bixina (A) e norbixina (B). o<smiles>COC(=O)/C=C/C(C)=C/C=C/C(C)=C/C=C/C=C(C)/C=C/C=C(C)/C=C/C(=O)O</smiles>

(A)<smiles>CC(/C=C/C=C(C)/C=C/C=C(C)/C=C/C(C)=C/C=C/C(=O)O)=C\C=C\C(=O)O</smiles>

(B)

Figura 3: estrutura da bixina (A) e norbixina (B).

O urucum possui aplicação bem pronunciada na sociedade, podendo-se citar o colorau, que é obtido por meio da mistura do pó pigmentoso de urucum com fubá, este na proporção de $90 \%$, sendo muito usado na culinária. A massa do urucum é usada em queimaduras, evitando formação de bolhas. 
Na cosmetologia pode ser empregado na fabricação de pós faciais, esmaltes, batons e creme bronzeador da pele. Há um segmento desse setor, chamado de fitocosméticos, do qual, o urucum faz parte. O pigmento extraído da semente, é oferecido em cápsulas que auxiliam e estabilizam a cor da pele em processos de bronzeamento. Na indústria, são usados para tingir tecidos, nas cores amarela, alaranjada e vermelha forte, e para intensificar e modificar certas tintas (MACCARI e MAZUCHOWSKI, 2006; BALIANE, 1982).

Segundo Costa (2007) a Bixa orellana possui vários constituintes químicos, podendo destacar os flavanóides (núcleo central identificado na figura 4, estrutura A), bem como, também o ácido gálico (figura 4, estrutura B), ácido alfitólico (figura 4, estrutura C), óleo essencial, além de vestígios de alcalóides.

Tem-se ainda entre esses compostos os carotenóides, ressaltando-se a bixina e a norbixina (figura 3), os quais apresentam maior importância comercial, por compor a maioria do pigmento vermelho extraído das sementes.<smiles>CC(=O)c1ccccc1OC1CC(=O)c2ccccc21</smiles>

(A)<smiles>O=C(O)c1cc(O)c(O)c(O)c1</smiles>

(B)<smiles>C=C(C)[C@@H]1CCC2(C(=O)O)CC[C@]3(C)C(CCC4[C@@]5(C)C[C@H](O)C(O)C(C)(C)C5CC[C@]43C)C12</smiles>

(C)

Figura 4: Estrutura básica dos flavonóides (A), ácido gálico (B), ácido alfitólico (C).

Em estudos realizados por Majolo (2009) mostrou-se que as tinturas de urucum apresentam em seus constituintes saponinas, flavonóides, taninos, alcalóides e esteróides. Enquanto, nas folhas do urucuzeiro, foram isolados compostos como flavonóides, diterpenos e óleo essencial, e outros como ácido gálico e pirogalol. Em extratos etanólicos das folhas e sementes foram revelados a presença de compostos como flavonóides, saponinas, outros compostos fenólicos, açúcares redutores e, nas sementes, ainda foi revelada a presença de óleos fixos (STRINGHETA; SILVA, 2008). 


\section{METODOLOGIA}

\subsection{Coleta do material vegetal}

O material vegetal utilizado na obtenção dos extratos de Bixa orellana $L$ (urucum) foi coletado no Sítio Cedro zona rural de São Miguel-RN, em horário matutino. O material foi previamente separado em folhas, caule e sementes.

\subsection{Obtenção dos extratos}

As diferentes partes da planta coletas, foram submetidas à secagem ao ar livre para retirada de umidade, durante 7 dias. Após esse tempo, os materiais vegetais foram moídos (em forrageira) e pesados, em seguida submetidos à processo de extração à frio, em proporção 1:3 planta/solvente, em separado com os solventes hexano e etanol, por 7 dias.

Posteriormente a extração, os solventes foram evaporados até a secura em evaporador rotatório obtendo-se os extratos etanólicos e hexânicos. Os extratos obtidos foram pesados para avaliação de seu rendimento. Calculou-se o rendimento de acordo com a fórmula:

$$
\operatorname{Re}=(\text { Mextrato } / \text { Mmaterial }) \times 100
$$

Em que:

$\operatorname{Re}=$ Rendimento total do extrato (\%); Mextrato = Massa do extrato seco (g); Mmaterial = Massa do material vegetal seco $(\mathrm{g})$.

\subsection{Testes fitoquímicos}

Os testes fitoquímicos foram realizados segundo metodologia proposta por MATOS 1997; COSTA, 1994; HARBORNE, 1998; SIMÕES et al.,2004. Os extratos obtidos foram submetidos aos testes de: fenóis, taninos, antocianinas, antocianidinas, flavonóides, leucoantocianidinas, catequinas, flavanonas, saponinas, antraquinonas, alcalóides, esteróides e triterpenóides. Todos os testes acima citados foram realizados em todos os extratos etanólicos, no entanto, apenas o de fenol, triterpenóides e esteróides aplicados aos extratos hexânicos.

\subsubsection{Teste para taninos e fenóis}

Para identificação de fenóis e taninos utilizou-se $4 \mathrm{~mL}$ de cada extrato vegetal, aos quais foram adicionadas 3 gotas de uma solução alcoólica de cloreto férrico (3\%) seguida de repouso à temperatura ambiente. A presença de fenóis e taninos foi determinada pela mudança de coloração.

\subsubsection{Teste para antocianinas, antocianidinas e flavonóides}

Em diferentes tubos de ensaio contendo cada um, $4 \mathrm{~mL}$ dos respectivos extratos foram submetidas aos seguintes procedimentos: um foi acidificado a $\mathrm{pH} 3,0$; o outro alcalinizado à $\mathrm{pH}$ 8,5 e o último a pH 11. Em seguida observou-se a mudança de coloração. 


\subsubsection{Teste para leucoantocianidinas, catequinas e flavanonas}

Dois tubos de ensaio contendo $3 \mathrm{~mL}$ do extrato foram submetidos, um, a processo de acidificação com $\mathrm{HCl}$ até $\mathrm{pH}$ 1-3 e o outro alcalinizado com $\mathrm{NaOH}$ até $\mathrm{pH} 11$. Estes foram aquecidos para observar a mudança de coloração.

\subsubsection{Teste para Saponinas}

O extrato do material vegetal foi dissolvido em metanol e água destilada com agitação contínua, formando-se duas frações a solúvel e a não solúvel. Retirada toda a parte solúvel usouse apenas a parte não solúvel, que mais uma vez foi adicionada água para retirar qualquer substância aquosa, após esse procedimento, essa solução foi agitada para observar a formação de espuma.

\subsubsection{Teste para Flavonóides}

Para a realização do teste de identificação de flavonóides, utilizou-se $0,5 \mathrm{~g}$ do extrato ao qual foi adicionado $10 \mathrm{~mL}$ de etanol. Em seguida foram realizadas algumas reações para caracterização dos constituintes.

a) Reação de Taubock: nessa reação evaporou-se $3 \mathrm{~mL}$ do extrato final em banho maria até a secura. Resfriou-se o resíduo e umedeceu-se com algumas gotas de acetona. Logo, adicionou-se alguns cristais de ácido bórico e ácido oxálico. Evaporou-se novamente até a secura evitando-se aquecimento prolongado. Em seguida dissolveu-se em $5 \mathrm{~mL}$ de éter etílico e observando-se sob luz UV.

b) Reação de Pew: evaporou-se em banho maria $3 \mathrm{~mL}$ do extrato final até a secura. Ao resíduo final adicionou-se $3 \mathrm{~mL}$ de metanol e uma pequena porção de zinco metálico. Em seguida, colocou-se aproximadamente 3 gotas de $\mathrm{HCl}$ concentrado.

c) Reação do Cloreto Férrico: em uma $1 \mathrm{~mL}$ do extrato final adicionou-se algumas gotas de $\mathrm{FeCl}_{3}$ a $2 \%$ e observou-se a mudança de coloração.

d) Reação do Cloreto de Alumínio: neste procedimento, umedeceu-se diferentes áreas de um papel de filtro com o extrato. Em seguida colocou-se sobre uma das manchas uma gota de cloreto de alumínio $5 \%$ em etanol e observou-se sob luz UV.

\subsubsection{Teste para Antraquinonas}

Para o referido teste, utilizou-se duas reações de caracterização:

a) Antraquinonas Livres: agitou-se $0,5 \mathrm{~g}$ do extrato com $10 \mathrm{~mL}$ de éter etílico. Logo após, acrescentou-se a solução $1 \mathrm{~mL}$ de amônia diluída e agitou-se. Após esse procedimento observouse a mudança de coloração.

b) Glicosídeos Antraquinônicos - Reação de Borntraeger: em 0,5g do extrato adicionou-se $20 \mathrm{~mL}$ de água e aqueceu-se à ebulição por 5 minutos. Após o resfriamento, filtrouse a solução. Em seguida, adicionou-se $10 \mathrm{~mL}$ de $\mathrm{HCl} 1 \mathrm{~N}$ e $3 \mathrm{~mL}$ de água oxigenada $30 \%$. Resfriouse e filtrou-se novamente a solução. Logo após extraiu-se duas vezes com $5 \mathrm{~mL}$ de éter etílico e as fases étereas foram juntas e agitadas com $3 \mathrm{~mL}$ de amônia diluída. 


\subsubsection{Teste para Alcalóides}

Preparo dos reagentes:

a) Reagente de Bouchardat ou Wagner - Solução de lodo 10N. Dissolveu-se $1 \mathrm{~g}$ de iodo em uma porção de água, em seguida dissolveu-se $2 \mathrm{~g}$ de iodeto de potássio e completou-se o volume para $100 \mathrm{~mL}$.

b) Reagente de Mayer - misturou-se 1,35g de cloreto de mercúrio com $60 \mathrm{~mL}$ de água; dissolveu-se $5 \mathrm{~g}$ de iodeto de potássio em $20 \mathrm{~mL}$ de água; misturou-se as soluções e completou-se o volume para $100 \mathrm{~mL}$ com água, em seguida agitou-se e filtrou-se.

c) Reagente de Dragendorff - dissolveu-se $8 \mathrm{~g}$ de subnitrato de bismuto em $20 \mathrm{~mL}$ de ácido nítrico $30 \%$. Logo após, dissolveu-se em separado $22,8 \mathrm{~g}$ de iodeto de potássio em volume mínimo de água. Em seguida, verteu-se pouco a pouco a primeira solução sobre a segunda e deixou-se em repouso por algumas horas e filtrou-se. Completou-se o volume com água para $100 \mathrm{~mL}$ e guardou-se ao abrigo da luz.

Para identificação de alcalóides utilizou-se $0,2 \mathrm{~g}$ do extrato e dissolveu-se em $1 \mathrm{~mL}$ de metanol, em seguida foi homogeneizado e alcalinizado com $10 \mathrm{~mL}$ de solução de carbonato de cálcio a $10 \%$. Logo após adicionou-se $25 \mathrm{~mL}$ de clorofórmio e, depois de homogeneizado, filtrouse a mistura para um funil de separação através de papel previamente embebido em clorofórmio, agitando-se o filtrado com $7 \mathrm{~mL}$ de $\mathrm{HCl} 2 \%$. Separou-se a camada superior para realização das reações de caracterização (precipitação) com os reagentes de Bouchardat, Mayer e Dragendorff, colocando-se uma gota do reagente ao lado de outra solução ácida em uma lâmina de microscópio, unindo-as posteriormente. O resultado foi observado pela visualização da reação sob luz ultravioleta.

\subsubsection{Teste para esteróides/triterpenóides (Lieberman-Burchard)}

Em um tubo de ensaio contendo $2 \mathrm{~mL}$ do extrato adicionou-se $2 \mathrm{~mL}$ de clorofórmio, em seguida a solução clorofórmica foi filtrada em um pequeno funil fechado com uma pequena bolinha de algodão para um segundo tubo de ensaio. Foi adicionado $1 \mathrm{~mL}$ de anidrido acético, e agitou-se suavemente, e acrescentou-se três gotas de ácido sulfúrico concentrado $\left(\mathrm{H}_{2} \mathrm{SO}_{4}\right)$, tornou-se a agitar, observando-se o desenvolvimento de cores.

\section{RESULTADOS E DISCUSSÃO}

\subsection{Rendimento dos extratos}

Inicialmente, foram obtidas as massas iniciais dos materiais vegetais. Em seguida, as massas de seus respectivos extratos, ao qual se aplicou a fórmula mencionada anteriormente, obtendo-se os rendimentos de cada extrato, podendo ser verificado na Tabela 1.

Tabela 1: Percentual das massas do extrato bruto de diferentes partes de Bixa orellana L.

\begin{tabular}{cccc}
\hline \multicolumn{4}{c}{ Extratos etanólicos } \\
\hline & Folha & Caule & Semente \\
\hline Massa inicial do material $(\mathrm{g})$ & 230 & 246 & 216 \\
\hline Massa do extrato $(\mathrm{g})$ & 19,02 & 5,67 & 9,8 \\
\hline
\end{tabular}




\begin{tabular}{cccc}
\hline Rendimento (\%) & 8,27 & 2,30 & 4,53 \\
\hline & Extratos hexânicos & & \\
\hline & Folha & Caule & Semente \\
\hline Massa inicial do material (g) & 252 & 298 & 454 \\
\hline Massa do extrato (g) & 5,54 & 1,0 & 11,16 \\
\hline Rendimento (\%) & 2,20 & 0,33 & 2,46 \\
\hline
\end{tabular}

Fonte: elaborada pelo próprio autor.

Apesar da ampla variedade de solventes conhecidos (líquidos extratores), são poucos os utilizados na extração dos compostos vegetais. Essa limitação de uso é devida a três aspectos principais: propriedades extrativas, adequação tecnológica, inocuidade fisiológica e fatores econômicos (PINTO, 2005). Diante desta abordagem, justifica-se que o bom rendimento dos extratos etanólicos devido sua polaridade, o que lhe confere uma melhor propriedade extrativa.

\subsection{Análise Fitoquímica}

As prospecções fitoquímicas realizadas, mostraram-se bastante eficientes na identificação das classes de metabólitos presentes nos extratos etanólicos e hexânicos da folha, caule e sementes do urucum.

\subsubsection{Teste para fenóis e taninos}

Os testes para taninos e fenóis apresentaram resultados negativos em todos os extratos investigados. Isso foi comprovado pela ausência de coloração ou formação de precipitado, pois coloração entre azul e vermelho, é indicativo de presença de fenóis, enquanto a formação de precipitado escuro de tonalidade azul indicaria a presença de taninos hidrolisáveis e a de coloração verde, de taninos condensados.

Em pesquisas realizada por Costa et al (2007); Stringheta e Silva (2008) foi possível identificar a presença de flavonóides na composição química do urucum. E como ressalta Simões et al (2001) os flavonóides representam um dos grupos fenólicos mais importantes e diversificados entre os produtos de origem natural. Sendo assim, acredita-se que a ausência e/ou presença de compostos fenólicos provavelmente sofre influência do ambiente em que a espécie foi coletada.

\subsubsection{Teste para antocianinas, antocianidinas, flavonóides}

Os testes para antocianinas, antocianidinas e flavonóides, basearam-se nas mudanças de $\mathrm{pH}$ e de coloração. As variações de cor indicam a presença de conforme a Tabela 02. Os extratos estão identificados pelas siglas:
E.E.F.U - Extrato Etanólico da Folha do Urucum
E.E.C.U - Extrato Etanólico do Caule do Urucum
E.E.S.U - Extrato Etanólico da Semente do Urucum 
Assim, E.E.F.U e o E.E.C.U apresentaram resultados negativos, para todos os testes. Apenas o extrato etanólico da semente do urucum (E.E.S.U) apresentou resultado positivo para flavonas, flavanóis e xantonas perceptível pela mudança de coloração para amarelo, em meio alcalino ( $\mathrm{pH}$ 11).

Tabela 02: Variações de coloração para testes de antocianinas, antocianidinas e flavonóides para os extratos etanólicos.

\begin{tabular}{|c|c|c|c|c|}
\hline Constituintes & Extratos & $\begin{array}{c}\text { Resultados } \\
\text { em pH }\end{array}$ & Extratos & Resultados em pH \\
\hline \multirow{3}{*}{ Antocianinas e antocianidinas } & (E.E.F.U) & Negativo & (E.E.F.U) & Negativo \\
\hline & (E.E.C.U) & Negativo & (E.E.C.U) & Negativo \\
\hline & (E.E.S.U) & Negativo & (E.E.S.U) & Negativo \\
\hline Flavonas, flavonóis e xantonas & & - & (E.E.S.U) & Positivo \\
\hline \multirow{3}{*}{ Chalconas e auronas } & (E.E.F.U) & Negativo & (E.E.F.U) & Negativo \\
\hline & (E.E.C.U) & Negativo & (E.E.C.U) & Negativo \\
\hline & (E.E.S.U) & Negativo & (E.E.S.U) & Negativo \\
\hline
\end{tabular}

Não realizado: -

As flavonas e os flavonóis agem como protetores químicos das células vegetais, contra os danos causados pela fotoxidação. Além disso, funcionam como sinais atrativos para insetos como abelha (FERREIRA; OLIVEIRA e SANTOS, 2008). Para Valdamiri (2008) esta classe de compostos possui atividades bioquímicas e farmacológicas conhecidas, tais como efeitos antioxidantes, anticarcinogênico, anti-inflamatório, antiproliferativo, antiangiogênico e antiestrogênico.

Segundo Ugaz (2001) o interesse crescente pelos compostos de xantonas é explicado devido suas propriedades farmacológicas, inibidor da monoaminaoxidase, atividade antipsicótica, efeitos da tuberculose, entre outros. Ainda segundo Corrêa (2009) as xantonas apresentam as mais variadas atividades biológicas, podendo citar a antioxidante, anti-inflamatória, anticancerígena, antibacteriana.

\subsubsection{Teste para leucoantocianidinas, catequinas, flavanonas}

Os testes para leucoantocianidinas, catequinas e flavonas também se basearam na mudança de coloração e $\mathrm{pH}$, conforme mostra a Tabela 4. De acordo com a metodologia adotada, os testes realizados em pH 3,0 (ácido) deverão apresentar coloração vermelha, quando houver presença de leucoantocianidinas; coloração vermelha amarelo-parda, quando houver presença de catequinas e coloração vermelha quando houver presença de flavanonas. No caso das flavanonas, o resultado positivo é associado a um teste de variação de cor, ocorrendo um vermelho alaranjado em meio de $\mathrm{pH} 8,5$. 
Tabela 4: Variações de coloração para testes leucoantocianidinas, catequinas, flavanonas para os extratos etanólicos.

\begin{tabular}{|c|c|c|c|c|c|c|}
\hline \multirow[b]{2}{*}{ Constituintes } & \multirow[b]{2}{*}{$\begin{array}{l}\text { Coloração } \\
\text { característica } \\
\text { em Ácido } \\
\text { (pH3,0) }\end{array}$} & \multicolumn{5}{|c|}{ Cor em meio } \\
\hline & & Extratos & Resultados & $\begin{array}{c}\text { Coloração } \\
\text { característica } \\
\text { em meio } \\
\text { Alcalino } \\
\text { (pH 8,5) }\end{array}$ & Extratos & Resultados \\
\hline \multirow[b]{3}{*}{$\begin{array}{c}\text { Leucoantocian } \\
\text { idinas }\end{array}$} & & E.E.F.U & Negativo & - & E.E.F.U & - \\
\hline & & E.E.S.U & Negativo & - & E.E.S.U & - \\
\hline & Vermelha & E.E.C.U & Negativo & - & E.E.C.U & - \\
\hline \multirow{4}{*}{ Catequinas } & & E.E.F.U & Negativo & - & E.E.F.U & - \\
\hline & Pardo- & E.E.S.U & Negativo & - & E.E.S.U & - \\
\hline & amarelada & E.E.C.U & Negativo & - & E.E.C.U & - \\
\hline & & E.E.F.U & Negativo & & E.E.F.U & - \\
\hline \multirow[t]{2}{*}{ Flavanonas } & Vermelha & E.E.S.U & Negativo & Vermelha-laranja & E.E.S.U & - \\
\hline & & E.E.C.U & Negativo & & E.E.C.U & Positivo \\
\hline
\end{tabular}

Não realizado: -

Deste modo, na análise realizada no E.E.F.U e E.E.S.U obteve-se resultados negativos tanto em meio ácido como alcalino. Porém o E.E.C.U mostrou indicação da presença de flavanonas, através do aparecimento de coloração vermelha laranja em meio alcalino.

\subsubsection{Teste para saponinas}

Todos os extratos etanólicos mostraram resultados positivos para saponinas, a partir da observação de uma espuma persistente e abundante. As saponinas despertam um grande interesse farmacológico, pois podem ser empregadas farmacologicamente, como expectorantes e diuréticos. Ainda são poucas as saponinas reportadas como substâncias isoladas (SIMÕES et al 2001).

\subsubsection{Teste para flavonóides}

Os testes para flavonóides foram caracterizados por reações com mudança de coloração: reação de taubock, reação de pew, reação de cloreto férrico e cloreto de alumínio. A Tabela 5 mostra o resultado dos testes para flavonóides. 
Tabela 5: Resultado dos testes para flavonoides nos extratos etanólicos.

\begin{tabular}{cccccc}
\hline & \multicolumn{5}{c}{ Reação de caracterização } \\
\cline { 2 - 5 } Extratos & Taubock & Pew & Cloreto Férrico & Cloreto de Alumínio \\
\hline E.E.F. U & + & - & + & - \\
\hline E.E.C. $U$ & + & - & + & - \\
\hline E.E.S. $U$ & + & + & + & - \\
\hline
\end{tabular}

Positivo (+); Negativo (-)

O resultado positivo da reação de taubock foi observado pela florescência, amarelo esverdeado, apresentada na luz UV. Enquanto, o resultado da reação de pew foi confirmado pela coloração vermelha. Na reação de cloreto de alumínio o resultado negativo foi notado pela ausência de coloração verde, amarelo ou ainda violáceo, na presença da luz UV.

Alguns trabalhos realizados com a fitoquímica da planta também relatam a presença de flavonóides, destacando-se o glucosídeo de apigenina, bisulfato de apigenina e hipoaletina, corroborando assim, com nossos achados.

Os flavonóides são grupo de interesse econômico e, principalmente, farmacológico, pois, possuem atividades antitumorais, anti-inflamatórias, antioxidantes, antivirais, entre outras (SHIRWAIKAR et al, 2004)

\subsubsection{Teste para antraquinonas}

A análise de antraquinonas também caracterizou-se por algumas reações e mudança de coloração em fase aquosa. Apenas o extrato E.E.S.U apresentou resultado positivo para antraquinonas livres, admitido pela coloração rósea apresentada pela camada aquosa. Todos os extratos etanólicos apresentaram resultado negativo para glicosídeos antraquinônicos, pela ausência de coloração rósea em camada aquosa.

\subsubsection{Teste para alcalóides}

Os testes para alcalóides foram avaliados por reação de caracterização (precipitação) com os reagentes: Wagner, Mayer, Dragendorff. Portanto, precipitado em pelo menos dois tubos indicou a presença de alcalóides. De acordo com a Tabela 6 percebe-se resultado positivo apenas nos extratos E.E.F.U e E.E.S.U, em que foi possível a formação de precipitado.

Tabela 6: Resultado dos testes para alcalóides.

\begin{tabular}{cccc}
\hline & \multicolumn{4}{c}{ Reagente } \\
\cline { 2 - 4 } Extratos & Wagner & Mayer & Dragendorff \\
\hline E.E.F. U & - & + & + \\
\hline E.E.C. U & - & - & + \\
\hline E.E.S. U & - & + & + \\
\hline
\end{tabular}

Positivo (+); Negativo (-) 
Os resultados positivos apontados nos extratos E.E.F.U e E.E.S.U para alcalóides comprovam o que afirma Majolo (2009) em sua pesquisa com tinturas de urucum. Importante ressaltar que a utilização de alcalóides se perde na história do tempo, pois já se retrata desde os primórdios da civilização, na forma de medicamentos, venenos e porções mágicas.

\subsubsection{Teste para triterpenóides e esteróides}

Em todos os extratos investigados para triterpenóides e esteróides os testes apresentaram resultados positivos, confirmados a partir da mudança de coloração azul evanescente seguida de verde. De acordo com Nunes (2013) os triterpenóides apresentam propriedades farmacológicas diversas, como anti-inflamatórias, hepatoprotetoras, analgésicas, antibióticas, antimicóticas, imunomoduladoras, virostáticas e tónicas. Os esteróides apresentam atividade anti-inflamatória comprovada.

\section{CONSIDERAÇÕES FINAIS}

Os resultados dos testes fitoquímicos adquiridos a partir desse estudo, contribuíram cientificamente para o conhecimento dos constituintes do urucum, coletado no Sítio Cedro, zona rural de São Miguel-RN, tal estudo permitiu confirmar a presença de flavanonas, flavonóis, xantonas, saponinas, flavonóides, antraquinonas livres, alcalóides, triterpenóides e esteróides em alguns dos extratos etanólicos e hexânicos.

Diante desta pesquisa, foi observado que algumas análises fitoquímicas realizadas apresentaram resultados semelhantes aos da literatura, tais como para flavanóides, alcalóides, esteróides e saponinas, enquanto outros apresentaram resultados diferentes para taninos e fenóis.

De acordo com a literatura estas classes de compostos já possuem atividades biológicas, farmacológicas e medicinais comprovadas, tais como antioxidante, anti-inflamatória, antialérgica, anticancerígena, antibacteriana, analgésicas, antibióticas, antimicóticas, imunomoduladoras, virostáticas, tónicas, expectorantes e diuréticos. Dessa forma, tais constituintes indicam o potencial do urucum na produção de fitoterápicos para o controle de enfermidades, como por exemplo, problemas na pele, dispepsia, queimaduras, entre outras aplicações.

\section{REFERÊNCIAS}

ALVES, R. W. (2005). Extração de Corantes de Urucum Por Processos Adsortivos Utilizando Argilas Comerciais e Colloidal Gas Aphrons. Dissertação de Mestrado, Universidade Federal de Santa Catarina, Florianópolis, Santa Catarina, Brasil.

BALIANE, A. (1982). Cultura do urucueiro. [Manual]. Empresa de Assistência e Extensão Rural do Estado do Rio de Janeiro (Vol. 2), Niterói, RJ. Brasil.

BARREIROS, A.L.B. (2000). Contribuição ao Estudo Fitoquímico de Dioclea lasiophylla. Dissertação de Mestrado, Universidade Federal da Bahia, Salvador, Bahia, Brasil. 
BEZERRA, D.A.C. (2008). Estudo Fitoquímico, Bromatológico e Microbiológico de Mimosa tenuiflora (Wild) Poiret e Piptadenia stipulacea (Benth) Ducke. Dissertação de Mestrado em Zootecnia, Universidade Federal de Campina Grande, Patos, Paraíba, Brasil.

CORRÊA, R.S. (2009). Xantonas Oxigenadas Bioativas: cristalização, estrutura e suas interações intra e intermoleculares. Dissertação de Mestrado em Ciências, Universidade de São Paulo, São Carlos, São Paulo, Brasil.

COSTA, C.K. (2007). Estudo Fitoquímico de Bixa orellana L., Bixaceae e Aplicação de seu Óleo em Formulação Cosmética. Dissertação de Mestrado em Ciências Farmacêuticas, Universidade Federal do Paraná, Curitiba, Paraná, Brasil.

COSTA, A.F. (1994). Farmacognosia (Vol. 3, 5a ed). Lisboa: Fundação Calouste Gulbenkian.

CUNHA, F.G. (2008). Estudo da Extração Mecânica de Bexina das Sementes de Urucum em Leite de Jorro. Dissertação de Mestrado em Engenharia Química, Universidade Federal de Uberlândia, Uberlândia, Minas Gerais, Brasil.

DORNELAS, C.S.M. (2010). Estudo de Maturação, Métodos de Descachopamento e Determinação do Teor de Bixina em Sementes de Urucuzeiro, Tese de Doutorado em Agronomia, Universidade Federal da Paraíba, Areia, Paraíba, Brasil.

FERREIRA, M.M.M; OLIVEIRA, A.H.C; SANTOS, N.S. (2008). Flavonas e Flavonóis: novas descobertas sobre sua estrutura química e função biológica. Revista Agroambiente On-line (2), 4, 57-60.

FUMAGALI, E.; GONÇALVES, R.A.C.; MACHADO, M.F.P.S.; VIDOTI, G.J.; OLIVEIRA, A.J.B. (2008). Produção de Metabólitos Secundários em Cultura de Células e Tecidos de Plantas: o exemplo dos gêneros Tabernaemontana e Aspidosperma. Revista Brasileira de Farmacognosia (18), 4, 627-641.

HARBORNE, J. B.; BAXTER, H. (1993). Phytochemical Dictionary. A handbook of Bioactive Compounds from Plants. London: Taylor e Francis.

MAJOLO, C. (2009). Atividade Antibacteriana in vitro de Diferentes Acessos de Bixa orellana L. (Urucum) e sua Relação com o Teor de Bixina Presente nas Sementes. Dissertação de Mestrado em Ciência e Tecnologia de Alimentos, Universidade Federal do Rio Grande do Sul, Porto Alegre, Rio Grande do Sul, Brasil.

MACCARI JÚNIOR. A.; MAZUCHOWSKI, J. Z. (2000). Produtos alternativos e desenvolvimento da tecnologia industrial na cadeia produtiva da erva-mate. Curitiba: Câmara Setorial Produtiva da Erva-Mate do Paraná.

MATOS, F. J. de A. (1997). Introdução à fitoquímica experimental. (2a. ed.) Fortaleza: EUFC.

NUNES, F. I. A. (2013). Caraterização estrutural de novos triterpenóides pentacíclicos. Dissertação de Mestrado em Química Farmacêutica Industrial, Universidade de Coimbra, Coimbra, Portugal.

PINTO, M. A. S. (2005). Técnicas de sepração e identificação aplicadas a produtos naturais. Monografia, Universidade Federal de Santa Catarina, Florianópolis, Santa Catarina, Brasil.

RICARDO, L. G. P.S. (2011). Estudos etnobotânicos e prospecção fitoquímica de plantas medicinais utilizadas na comunidade do Horto, Juazeiro do Norte (CE). Dissertação de Mestrado em Ciências Florestais, Universidade Federal de Campina Grande, Patos, Paraíba, Brasil. 
SIMÕES, C. M. O. ; SCBENKEL, E. P.; GOSMAM, G; MELlO, J. C. P.; MENTZ, L. A.; PETROVICK, P. R. (2001). Farmacognosia: da planta ao medicamento. (3a ed.) Porto Alegre: UFSC.

SIMÕES, C.M.O.; SCHENKEL, E.P.; GOSMANN, G.; MELLO, J.C.P.; MENTZ, L. A.; PETROVICK, P. R. ( 2004). Farmacognosia: da planta ao medicamento. (5a. ed.) Porto Alegre: Ed. UFRGS.

STRINGHETA, P.C; SILVA, P.I. (2008). Pigmentos de Urucum Extração, Reações Químicas, Usos e Aplicações. Viçosa: Suprema.

SHIRWAIKAR, A.; RAJENDRAN, K.; KUMAR, C.D, BLODA, R. (2004). Antidiabetic activity of aqueous leaf extract of Annona squamosa in streptozotocin-nicotinamide type 2 diabetic rats. Journal of Ethnopharmacology. 91, 171.

SOARES, B.V. (2008). Estudo fitoquímico e antifúngico de extratos de plantas contra Microsporum canis e Cândida spp. Isolado de cães. Dissertação de Mestrado em Ciências Veterinárias, Universidade Estadual do Ceará, Fortaleza, Ceará, Brasil.

SOUZA, L.F. (2011). Ação Antioxidante de Compostos Bioativos do Urucum - Bixina. Dissertação de Mestrado em Ciência e Tecnologia de Alimentos, Universidade Federal do Rio Grande do Sul, Porto Alegre, Rio Grande do Sul, Brasil.

VIEGAS JR. C; BOLZANI, V.S. (2006). Os produtos naturais e a química medicinal moderna. Química Nova, 29 (2), 326-337.

UGAZ, O. L. (2001). Manual de Fitoterapía. Lima: EsSalud.

VALDAMERI, G. (2008). Efeitos da Flavona sobre o Metabolismo Mitocondrial. Dissertação de Mestrado em Ciências - Bioquímica, Universidade Federal do Paraná, Curitiba, Paraná, Brasil. 